\title{
Tele-guidance based Navigation System for the Visually Impaired and Blind Persons
}

\author{
Babar Chaudary ${ }^{1}$, Petri Pulli ${ }^{1}$, Iikka Paajala ${ }^{2}$, and Eliud Keino ${ }^{3}$ \\ Department of Information Processing Science (TOL) \\ University of Oulu, Finland \\ \{babar.chaudary, petri.pulli\}@oulu.fi \\ \{Iikkaa.paajala, eliud.keino\} egmail.com
}

\begin{abstract}
The design and development of tele-assistance services have taken a great consideration in the domain of healthcare lately. With the growing proportion of dependent people (ageing, disabled users) in the society, teleassistance and tele-monitoring platforms will play a significant role to provide an efficient and economical remote care. It will allow aged or disabled persons to maintain their independence and lessen the burden and cost of care by caregivers. The concept of proposed tele-guidance system is based on the idea that a blind pedestrian can be assisted by spoken instructions from a remote caregiver who receives a live video stream from a camera carried by the visually impaired persons (VIP). The ICT based assistive tools have acceptance issues by visually impaired persons. It is important while designing navigation tools for the VIP to keep in view the factors that restrain them from the adoption of assistive technology. This paper presents a tele-guidance based navigation assistance system for the VIP and blind persons and reports a qualitative study about attitude of VIP towards technological navigation assistance.
\end{abstract}

Keywords: Tele-assistance, Tele-presence, Real-time, Navigation, Remote care, Caregiver, Visually Impaired, Blind, Acceptance, Qualitative, UTAUT

\section{Introduction}

Vision loss is a serious impairment that deprives a human of approx. 80-90\% perceptual abilities and has a detrimental effect on professional, social and personal quality of life. It is estimated that there are 285 million VIP in the world, 39 million of those being completely blind. $82 \%$ of the blind people [1]. Even in modern societies, common understanding of blindness and the needs of the VIP are poorly identified. The White Cane and more rarely a Guide Dog are the primary mobility aids that are mainly associated with this disability. In spite of recent remarkable advancements in information and communication technologies (ICT) and electronics, the devices that are termed as Electronic Travel Aids (ETA) are very slowly fighting their ways into the community of the VIP. In fact, no single ETA has been widely accepted by the VIP and blind as a useful aid [2]. 
ETA is the general term encompassing a large class of assistive devices. The idea of sensory substitution, i.e. replacing lack of stimuli from one sense by appropriate stimuli for another sense is the operating principle of all ETAs [2].

Following is a functional, rather than technological classification of ETAs:

1. Obstacle Detectors

2. Environment Imagers

3. Orientation \& Navigation systems (ONSs)

The first two classes of ETAs are personal (wearable) devices that scan the environment in personal and near spaces. These devices have the task to assist VIP to intercept obstacles on their path. On the other hand, the third group is systems that offer sensing of far-spaces and can acquire data from larger scale distributed networks, e.g. GPS, GIS, Digital Maps, and through wide access to the Internet and wireless communication networks (e.g. RFID, Bluetooth, Wi-Fi, and GSM). An innovative class of ONSs is based on guiding the VIP by a remote human guide termed as Tele-assistance/Tele-guidance systems. [3].

The first reported system for remote guidance of the blind was the system developed at the Brunel University, UK [4]. Three ICT technologies were combined to offer the Tele-assistance functionality; namely, GPS, GIS and video/voice transmission over the $3 \mathrm{G}$ mobile network. [5] was a Tele-assistance system developed using GPS, Digital maps, Bluetooth, and voice/video link was established over the GSM network within the High-Speed Downlink Packet Access (HSDPA). The system comprised of an ultra-mobile laptop computer worn in a shoulder bag, a digital webcam, and a GPS receiver attached to the shoulder strap, and a single-ear headphone with a microphone and the assistant who remotely aided the VIP used any PC with a public IP address. In [6], the authors developed a remote guidance system where the VIP was equipped with a digital camera, a GPS receiver and a headset. Internet and GSM connections transmitted video/audio information and GPS data between the remote operator and the user. Similar tele-assistance systems were developed in [7], [8], and [9].

These systems either used bulky back packs or special purpose mobile terminals to be carried by the VIP. This fact affected the acceptability of such systems by VIP at large. The advancement in computation capabilities of mobile devices and electronics miniaturization presented newer possibilities for developers to develop more userfriendly tele-guidance systems for the VIP. The proposed tele-guidance system enables remote caregiver to assist VIP through voice or vibration using live video feed of VIP's field of view and relative IoT data.

\section{System Description}

System comprises of two modules, VIP's terminal and remote caregiver's terminal.

\subsection{VIP's Terminal}

VIP's terminal comprises of four components: 
1) Smart Phone: It provides connectivity with the remote caregiver's terminal. The readily available sensors e.g. GPS and network connectivity are used to provide remote caregiver with real time IoT data about VIP.

2) Bluetooth Webcam: A Bluetooth webcam connected to the smart phone through Bluetooth is mounted on the chest of the VIP. It sends real time video of the field of view of the VIP.

3) Bluetooth Headset (Earpiece, Speaker): The Bluetooth head set is used for voice communication.

4) Smart Cane: The Smart Cane contains tactile braille cell, directional vibrators, and Bluetooth interface.

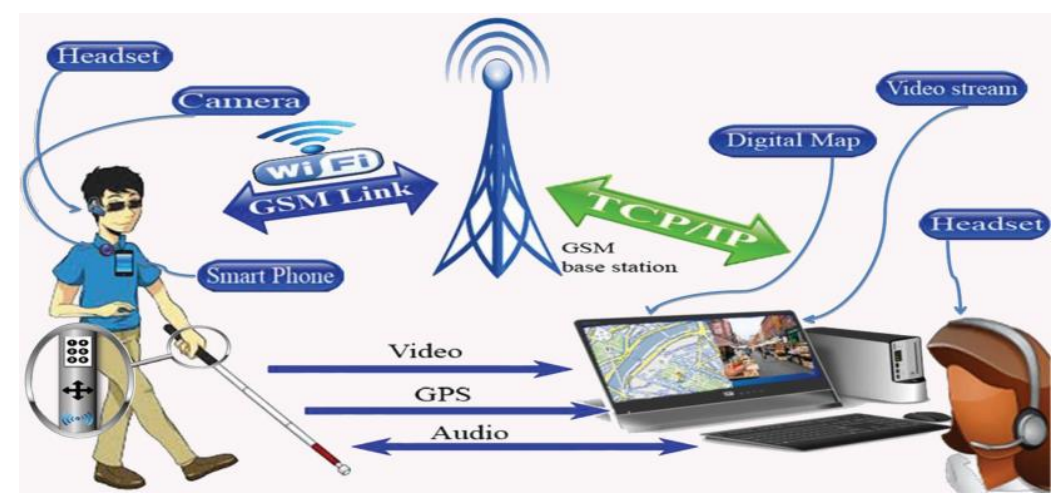

Figure 1. Tele-guidance system concept

The VIP initiates a video call to pre-configured remote caregiver in need of assistance. The VIP receives guidance either through Directional Vibrators, voice commands, or Tactile Braille Cell. During the tele-guidance session, VIP will be able to mute the voice of the remote caregiver anytime if she wants to make sense of the surroundings by listening proximity sounds. The remote caregiver will get a notification about voice muting. VIPs will be able to configure more than one person as caregiver. If either of those higher in priority is not available, the help call will be automatically transferred to the one available. The selection of caregiver and hand over can also be based on need based support.

\subsection{Remote Caregiver's Terminal}

The remote caregiver can either use a workstation, tablet or phablet as terminal. It receives and initiates the VoIP video calls and renders VIP's real-time location coordinates. As VIP can configure many people as his caregiver, the system will help caregivers to mediate time and load of the assistance through availability status info. It will be studied if there is a need for the caregiver to override voice muting by VIP.

The figure 2 shows the system's communication and response schematic sequence.

\subsection{Technologies}

The technologies used for different features of the proposed tele-guidance system are: 
1) Encrypted Communication: To support privacy between VIP and remote caregiver, encrypted voice, video, and location data communication over the internet will be used. Linphone API [10] that supports ZRTP protocol will be used to implement communication over the internet functionality [11].

2) Network Connectivity: Wi-Fi or GSM based internet connection will be used for making VOIP calls and sending real time GPS coordinates of VIP.

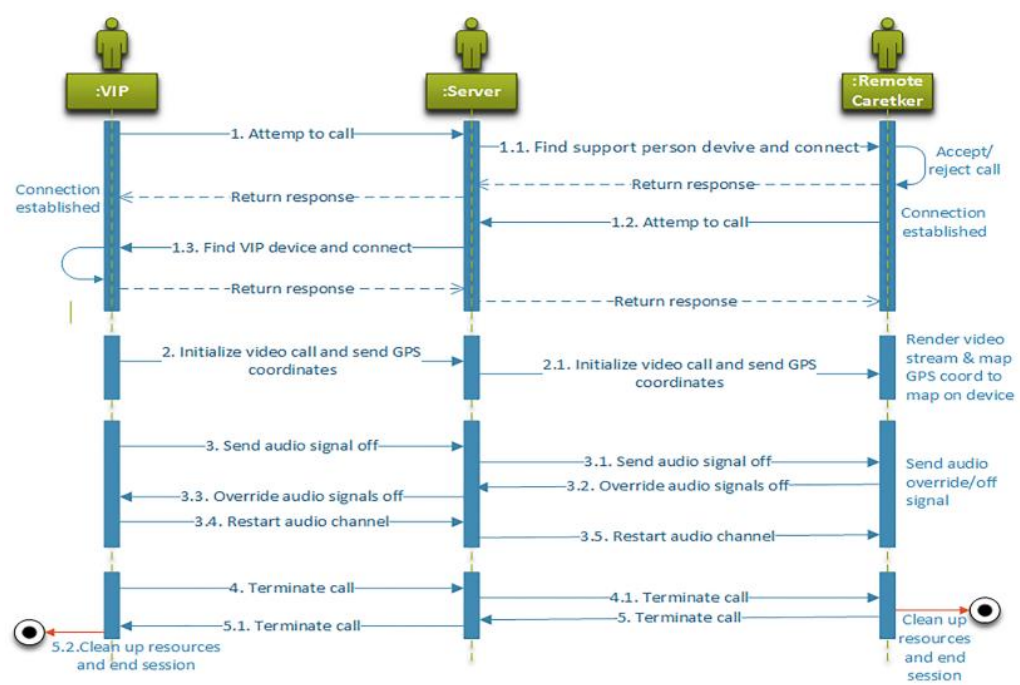

Figure 2. The communication and response schematic

\section{Usability Testing}

The usability testing will be conducted with real blind and VIP in three countries i.e. Finland, Pakistan, and Sweden as part of the ongoing qualitative study [12].

Usability testing by VIP:

- 1st phase: VIP initiated tele-guidance session and followed voice commands and tactile guidance by remote caregiver to navigate.

- 2nd phase: User muted the voice.

Usability testing by remote caregiver:

- 1st phase: The remote caregiver received a tele-guidance VoIP video call from the VIP and guided him through voice/vibration to navigate.

- 2nd phase: Remote caregiver gets indication voice about channel muting.

\section{Study for Acceptance of Technological Navigation Assistance Aids by VIP}

This study uses an extended version of Unified Theory of Acceptance and Use of Technology (UTAUT2). This model can be used by organizations to gain knowledge on improving the design and marketing of their consumer product [13]. The question 
set was modified to suit the VIP [APPENDIX A]. The UTAUT2 model constructs are performance expectancy (PE), effort expectancy (EE), social influence (SI), facilitating conditions (FC), hedonic motivation (HM), price value (PV) and habit (HA). The constructs are moderated also by age and gender which are asked by background questions (BG). Because the questionnaire is about assistive tools and for special group, we felt that some original UTAUT [14] questions should be included, especially from group of anxiety (ANX) and attitude (ATT), which had been dropped from the UTAUT2 model. These include questions assessing the potential for specific assistive technologies for the purposes of developing prototypes (SPE).

\subsection{Preliminary results of acceptance study}

19 VIP and blind are interviewed (10 female, 9 male, aged 21-82) in Oulu region in Finland. Our study supports earlier mentioned fact that no single ETA has been widely accepted by the VIP and blind people. None of the sample group used ETAs, and in fact had never even tried those. It seems that there may be too little information available on ETAs. 9 of the sample group didn't know enough on available tools, 9 perceived that they do have enough information on available tools.

10 participants did like the idea of sending their location information to person(s) close to them. Only 5 did object this matter. However 12 wanted select themselves the moments when they are being located. Only 1 participant would have given permission to location data when needed when support person would have been the spouse. 14 were willing to change daily routines if received a new kind of assistive tool. 13were willing to spend money on new kind of tools, and almost everyone was willing to spend time to learn use a new kind of tool.

An accompanying qualitative study addresses caregivers' needs and acceptance of navigation caretaking tools and services [15].

\section{Future Research}

Future research will focus on experiments in different outdoor environments and development of efficient navigation training methods for VIP and remote caregiver. The focus will be on how to address and negotiate the situation if remote connection is lost, reduction mechanism of communication delay, and if some miscommunication or non-availability occurs between the VIP traveler and remote caregiver.

\section{Conclusion}

In this article, a tele-guidance navigation system for VIP in was presented. The approach of the system is based on the idea that a VIP/blind pedestrian can be assisted by spoken instructions from a remote caregiver who receives a video stream from a camera carried by the VIP. The scenarios for the testing of overall system for both VIP and remote caregiver to evaluate the usability were presented. A qualitative study to investigate attitude of VIP and blind persons towards navigation assistance tools was also presented. 


\section{Acknowledgement}

This paper has been written as part of the ASTS (Assisted Living for Senior Citizens) Project funded by Academy of Finland and Japan Science technology Agency (JST).

\section{References}

1. Global data on visual impairments 2010 . http://www.who.int/blindness/GLOBALDATAFINALforweb.pdf?ua=1

2. N Bourbakis (2008), Sensing Surrounding 3-D Space for Navigation of the Blind, IEEE Engineering in Medicine and Biology Magazine, Jan/Febr 2008, pp. 49-55.

3. Garaj, V., Hunaiti, Z., \& Balachandran, W. (2010). Using remote vision: the effects of video image frame rate on visual object recognition performance. Systems, Man and Cybernetics, Part A: Systems and Humans, IEEE Transactions on, 40(4), 698-707.

4. V. Garaj, R. Jirawimut, P. Ptasinski, F. Cecelja and W. Balachandran: "A system for remote sighted guidance of visually impaired pedestrians", British Journal of Visual Impairment,vol. 21, pp. 55-63, 2003.

5. Bujacz, M., Baranski, P., Moranski, M., Strumillo, P., \& Materka, A. (2008, September). Remote mobility and navigation aid for the visually disabled. In Proc. 7th Intl Conf. on Disability, Virtual Reality and Assoc. Technologies with Art ArtAbilitation, in PM Sharkey, P. Lopesdos-Santos, PL Weiss \& AL Brooks (Eds.) (pp. 263-270).

6. P. Baranski, M. Polanczyk, and P. Strumillo. A remote guidance system for the blind. In Proc. IEEE Int. Conf. on e-Health Networking Applications and Services, pages 386-390, 2010.

7. M. Bujacz, P. Baranski, M. Moranski, P. Strumillo, and A. Materka. Remote guidance for the blind - A proposed teleassistance system and navigation trials. In Proc. Int. Conf. on Human System Interaction, pages 888-892, 2008.

8. S. Koley and R. Mishra. Voice operated outdoor navigation system for visually impaired person. Int. J. of Engineering Trends and Technologies, 3(2), 2012.

9. Z. Hunaiti, V. Garaj, and W. Balachandran. A remote vision guidance system for visually impaired pedestrians. Int. J. of Navigation, 59(3):497-504, 2006.

10. http://www.linphone.org/

11. https://silentcircle.com/faq-zrtp

12. Chaudary, B., Petri Pulli. Smart Cane Outdoor Navigation System for Visually Impaired and Blind persons, - Journal of Communication Disorders, Deaf Studies, \& Hearing Aids. 2014, 2: 125

13. Venkatesh, V., Thong, J.Y.L., \& Xu, X. (2012). Consumer acceptance and use of information technology: Extending the unified theory of acceptance and use of technology. MIS Quarterly vol 36. No 1. pp. 157-178.

14. Venkatesh, V., Morris, M.G., Davis, G.B. \& Davis, F.D. (2003). User acceptance of information technology: Toward a unified view. MIS Quarterly vol 27, No. 3, pp. 425478.

15. Mia Hautala., Niina S Keränen., Eeva Leinonen., Maarit Kangas., Timo Jämsä, (2016). ICT Use in Family Caregiving of Elderly and Disabled Subjects. In EAI International Conference on IoT and Big Data Technologies for HealthCare 
Appendix: A

\begin{tabular}{|c|c|c|}
\hline \multicolumn{3}{|r|}{ The Questionnaire with UTAUT Constructs } \\
\hline Serial \# & Construct & Questions \\
\hline 1 & $\mathrm{BG}$ & Age \\
\hline 2 & $\mathrm{BG}$ & Gender \\
\hline 3 & BG & $\begin{array}{l}\text { Did you acquire visual impairment with birth or did you lost } \\
\text { vision? How long ago? }\end{array}$ \\
\hline 4 & $\mathrm{BG}$ & What is your visual acuity? \\
\hline 5 & SP & $\begin{array}{l}\text { Do you have a support person(s) whom you can contact when } \\
\text { you need help? Which hours available? }\end{array}$ \\
\hline 6 & PEx, TA & $\begin{array}{l}\text { Do you use smartphone or any other mobile device? What } \\
\text { brand? Which apps? }\end{array}$ \\
\hline 7 & PEx & Do you use white cane? When / why did you start using it? \\
\hline 8 & PEx, TA & $\begin{array}{l}\text { Have you used any other navigation assistance? Did you stop } \\
\text { using it? Why? }\end{array}$ \\
\hline 9 & $\begin{array}{l}\text { PEx, RO, } \\
\text { IP }\end{array}$ & In what situations do you use navigation assistance? \\
\hline \multicolumn{3}{|r|}{ Statements } \\
\hline 10 & $\mathrm{HM}$ & Navigation assistance makes going outdoors more pleasant. \\
\hline 11 & $\mathrm{HM}$ & I like using navigation assistance. \\
\hline 12 & PV & Navigation assistance tools are reasonably priced. \\
\hline 13 & HA & Using navigation assistance has become a habit to me. \\
\hline 14 & $\mathrm{PE}$ & I need navigation assistance every time I go outdoors. \\
\hline 15 & $\mathrm{PE}$ & $\begin{array}{l}\text { In my opinion navigation assistance is useful when I am } \\
\text { outdoors. }\end{array}$ \\
\hline 16 & $\mathrm{PE}$ & Navigation assistance increases the speed of doing chores. \\
\hline 17 & $\mathrm{PE}$ & $\begin{array}{l}\text { If I use navigation assistance, I will increase my chances to } \\
\text { get where I want. }\end{array}$ \\
\hline 18 & $\mathrm{EE}$ & I find navigation assistance tools easy to use. \\
\hline 19 & $\mathrm{EE}$ & Learning to use navigation assistance tools is easy for me. \\
\hline 20 & SI & $\begin{array}{l}\text { People, who are important to me, think that I should use } \\
\text { navigation assistance. }\end{array}$ \\
\hline 21 & IP & $\begin{array}{l}\text { I find it annoying when surrounding people notice I am } \\
\text { visually impaired. }\end{array}$ \\
\hline 22 & SI & The society has been supportive in the use of assistive \\
\hline 23 & SI & $\begin{array}{l}\text { Instructors or medical staff have been supportive in the use of } \\
\text { assistive }\end{array}$ \\
\hline 24 & $\mathrm{FC}$ & My knowledge of using navigation assistance is sufficient. \\
\hline 25 & $\mathrm{FC}$ & $\begin{array}{l}\text { If I have problem navigation assistance, I know from who I } \\
\text { ask help. }\end{array}$ \\
\hline 26 & ANX & I feel nervous using navigation assistance. \\
\hline 27 & ANX & Navigation assistance is somewhat intimidating. \\
\hline 28 & ATT & Using navigation assistance is a good idea. \\
\hline
\end{tabular}




\begin{tabular}{|c|c|c|}
\hline 29 & ATT & Navigation assistance makes me feel safe. \\
\hline 30 & PV & $\begin{array}{l}\text { I am willing to spend money in order to buy new navigation } \\
\text { assistance. }\end{array}$ \\
\hline 31 & $\mathrm{PV}, \mathrm{RO}$ & $\begin{array}{l}\text { I am willing to spend my time in order to learn to use new } \\
\text { navigation assistance. }\end{array}$ \\
\hline 32 & RO & $\begin{array}{l}\text { I am willing to change my daily routines, if I receive a new } \\
\text { kind of navigation assistance. }\end{array}$ \\
\hline 33 & 33 & $\begin{array}{l}\text { I think that people close to me are willing to change their daily } \\
\text { routines, if I receive a new kind of navigation assistance. }\end{array}$ \\
\hline 34 & IP, SPE & It is good that people close to me know my location. \\
\hline 35 & IP, SPE & $\begin{array}{l}\text { I would like to select when people close to me know my } \\
\text { location. }\end{array}$ \\
\hline
\end{tabular}

